\title{
AVALIAÇÃO DE QUATRO GENÓTIPOS DE SORGO PELA TÉCNICA "in vitro" SEMI-AUTOMÁTICA DE PRODUÇÃO DE GASES
}

\author{
ROBERTO TOLEDO DE MAGALHÃES ${ }^{1}$, LÚCIO CARLOS GONÇALVES ${ }^{2}$, ROGÉRIO MARTINS \\ MAURÍCIO ${ }^{3}$, JOSÉ AVELINO S. RODRIGUES ${ }^{4}$, IRAN BORGES ${ }^{2}$, NORBERTO M. RODRIGUES ${ }^{2}$, \\ ELOÍSA O. S. SALIBA ${ }^{2}$, VERA LÚCIA DE ARAÚJO ${ }^{5}$
}

\author{
${ }^{1}$ Prof. Adjunto do Dep. de Zootecnia da UCG - Goiânia-GO - robertotoledo@ ucg.br (Av. Universitária, 1069-Setor \\ Leste Universitário, CEP. 74605-010, Cx postal 86 (autor para correspondência) \\ ${ }^{2}$ Prof. Adjunto da Escola de Veterinária da UFMG-Belo Horizonte, MG \\ ${ }^{3}$ Pesquisador da Fundação Ezequiel Dias. Rua Conde Pereira Carneiro, 80, Belo Horizonte - MG, CEP. 30350-110 \\ ${ }^{4}$ Pesquisador da Embrapa Milho e Sorgo - Sete Lagoas, MG \\ ${ }^{5}$ Aluna de doutorado da Escola de Veterinária da UFMG
}

Revista Brasileira de Milho e Sorgo, v.5, n.1, p.101-111, 2006

\begin{abstract}
RESUMO - Neste ensaio, foram estudadas a cinética de fermentação e a degradabilidade in vitro de quatro genótipos de sorgo (ATF53*9929036, ATF54*9929036, CMSXS217*9929012 e Volumax), através da técnica in vitro semi-automatica de produção de gases. Os tempos de incubação utilizados para a produção de gases foram: 2, 4, $6,8,10,12,15,18,21,24,30,36,48,60,72$ e 96 . Para a degradabilidade in vitro, utilizaram-se os tempos $6,12,24,48,72$ e 96 . O coeficiente de determinação obtido entre a produção acumulativa de gases e degradabilidade da materia seca foi de $\mathrm{r}^{2}=0,99$, demonstrando que os gases oriundos da fermentação representam a fermentabilidade dos substratos. O genótipo Volumax apresentou numericamente a maior taxa de fermentação $(\mu)(0,043$ (mL/g de MS/h), com a menor "lag phase" (L) (1 h e 16 min). Os demais genótipos apresentaram valores de $\mu$ entre 0,038 e $0,034 \mathrm{~mL} / \mathrm{g}$ de $\mathrm{MS} / \mathrm{h}$ e de $\mathrm{L}$ entre $1 \mathrm{~h}$ e $50 \mathrm{~min}$ e $1 \mathrm{~h}$ e $72 \mathrm{~min}$. Os resultados deste experimento indicam o genótipo Volumax como o mais promissor para a produção de silagem.
\end{abstract}

Palavras-chave: forragem, ruminante, valor nutritivo, digestibilidade

\section{EVALUATION OF FOUR SORGHUM GENOTYPES USING THE SEMI AUTOMATED IN VITRO GAS PRODUCTION}

\begin{abstract}
The objective of this study was to evaluate the ruminal fermentation kinetics and in vitro dry matter degradability of four genotypes of sorghum (ATF53*9929036, ATF54*9929036, CMSXS217*9929012 e VOLUMAX) using the semi-automated gas production technique. Incubation times adopted were 6, 12, 24, 48, 72 and $96 \mathrm{~h}$, and the frequency of gas production collections were: 2, 4, 6, 8, 10, 12, 15, $18,21,24,30,36,48,60,72$ and $96 \mathrm{~h}$. The coefficient of determination resulting from cumulative gas production data $\left(\mathrm{r}^{2}=0.99\right)$ and dry matter degradability showed that the gas produced represents the substrates fermentability. The VOLUMAX genotype showed a higher rate of fermentation $(\mu)(0.043(\mathrm{~mL} / \mathrm{g} \mathrm{DM} / \mathrm{h})$, with lower lag phase $(\mathrm{L})(1 \mathrm{~h}$ e $16 \mathrm{~min})$.
\end{abstract}


The other genotypes showed $\mu$ values from 0.038 to $0.034 \mathrm{~mL} / \mathrm{g} \mathrm{DM} / \mathrm{h}$, and $\mathrm{L}$ from $1 \mathrm{~h}$ 50 to $1 \mathrm{~h}$ e 72 . These results indicated that VOLUMAX genotype is better for silage production.

Key words: forage, ruminant, nutricional value, digestibility.

Nos trópicos, a existência de dois períodos distintos, estação das águas e estação da seca, determina a abundância na produção de volumosos em uma época e escassez extrema na outra. Conseqüentemente, o desempenho dos rebanhos fica limitado, pela falta de oferta de alimentos na época seca do ano. Dessa forma, o armazenamento do excesso de forragem proveniente da época das águas, para utilização no período da seca, constitui estratégia de grande impacto na viabilidade da atividade pecuária (Cabral et al., 2002).

O valor nutritivo de um alimento está associado à sua composição química e ao nível de aproveitamento dos nutrientes. Para os ruminantes, a associação da forrageira com os microrganismos do rúmen permite a utilização indireta de carboidratos estruturais refratários à atuação das enzimas dos animais superiores.

Segundo Russell et al. (1992), além das características peculiares das frações nutritivas constituintes, os alimentos consumidos pelos ruminantes são transformados pelos microrganismos ruminais, impedindo a predição do desempenho somente a partir dos componentes dietéticos. Assim, a qualidade das forragens está relacionada não só a sua composição química, mas também à dimensão do seu aproveitamento pelos animais.

As regiões tropicais caracterizam-se pelo elevado número de espécies forrageiras com grande potencial para serem usadas na alimentação de ruminantes. A planta de sorgo, segundo Rodrigues et al. (2002), é uma das espécies mais adaptadas à produção de silagem, apresentando facilidade de cultivo, altos rendimentos e boa qualidade nutricional. Apresenta um sistema radicular profundo (mais de $60 \mathrm{~cm}$ ), denso e ramificado, o que favorece uma grande faixa de solo a ser explorada pela planta e a boa produção em lugares com baixas médias pluviométricas (Vega \& Esperance, 1984).

$\mathrm{Na}$ tentativa de aliar produtividade de matéria seca e valor nutritivo, tem-se procurado desenvolver híbridos de sorgo que tenham equilíbrio entre colmo, folha e panícula (Brito et al., 1999). Estudos comparativos entre híbridos são de suma importância em programas de melhoramento genético e, conseqüentemente, para recomendar aos produtores os híbridos ou cultivares cujas silagens tenham a melhor relação produção e valor nutritivo.

A variabilidade genética dessa espécie permitiu o desenvolvimento de trabalhos de melhoramento que, segundo Pedreira et al. (2003), proporcionaram a obtenção de um grande número de híbridos. Cada um desses materiais apresenta características agronômicas e valor nutritivo diferentes, com consequientes variações quanto à produtividade e padrões de fermentação, quando utilizados para silagens. Esses fatores, de acordo com Cândido et al. (2002) e Pedreira et al. (2003), podem afetar diretamente o desempenho dos animais, tornando evidente a necessidade de estudos que conduzam à seleção de híbridos para silagens com alto valor nutritivo, mais adequados ao sistema de produção animal. 
Várias metodologias têm sido utilizadas para determinar as quantidades e relações dos nutrientes necessárias para uma ótima resposta microbiana e animal, através das predições da medida com que esses nutrientes tornam-se disponíveis no rúmen. Em razão de a determinação do valor nutricional das forrageiras ser extremamente importante, novas técnicas têm sido constantemente desenvolvidas com o intuito de facilitar a determinação do valor nutricional desses alimentos. Os métodos biológicos capazes de simular o processo digestivo, através de microorganismos ruminais in vitro (Tilley \& Terry, 1963) ou in situ (Ørskov et al., 1980), têm sido utilizados como alternativa ao método in vivo para a avaliação de forrageiras. Entretanto, os métodos in vitro e in situ não avaliam a cinética da digestão ou superestimam a fermentação ruminal, respectivamente.

O estudo da digestibilidade pelo método in vivo é oneroso, demanda tempo e mão-de-obra, além de avaliar número limitado de substratos. As técnicas in vitro têm sido, então, utilizadas para a determinação da qualidade nutricional de alimentos sendo estas relacionadas com o consumo e a digestibilidade pelo animal. A técnica in vitro semi-automática de produção de gases (Maurício et al., 1999) tem a capacidade de avaliar grande número de substratos e descrever a cinética de fermentação ruminal.

A técnica in vitro de produção de gases é capaz de simular o ambiente ruminal (Theodorou et al., 1994), além de descrever a cinética de fermentação ruminal e estimar o consumo (Ørskov, 1992). Dessa forma, esta tem se tornado uma opção para os estudos de forrageiras (Getachew et al., 1998). Devido às limitações impostas pela técnica in situ e in vitro, o método que mede a produção acumulativa dos gases vem sendo utilizado com sucesso para a estimativa das taxas de digestão das frações solúveis e insolúveis dos carboidratos, com base no princípio de que os gases produzidos são provenientes do metabolismo microbiano, partindo da fermentação do material incubado (Pell \& Schofield, 1993; Malafaia et al., 1998).

O modelo de produção de gases em relação à digestão da fibra e ao crescimento microbiano assume que a produção de massa celular bacteriana e de gases é proporcional à quantidade de substrato digerido (Schofield et al., 1994). Essa produção de gases é gerada diretamente do metabolismo de carboidratos por oxidação $\left(\mathrm{CO}_{2}\right)$ ou redução $\left(\mathrm{CH}_{4}\right)$ dos produtos finais e, também, pela reação dos AGV com solução tampão.

Blümmel \& Ørskov (1993) relatam que a técnica de produção de gases é basicamente semelhante ao descrito por Tilley \& Terry (1963), em que o substrato é incubado com líquido ruminal. A diferença está no fato de que a produção de gases é reflexo da fermentação total do substrato e, conseqüentemente, do desaparecimento da MS.

A técnica de produção de gases vem merecendo grande atenção por parte dos pesquisadores, nos últimos anos, devido, entre outras vantagens, ao fato de possibilitar o estudo da cinética de fermentação, preservar a amostra a cada coleta de dados e permitir a detecção das frações solúveis dos alimentos para a fermentação ruminal. A técnica in vitro semi-automática de produção de gases (Maurício et al., 1999) utiliza um transdutor digital de pressão para mensuração dos gases produzidos em frascos de fermentação com ambientes anaeróbicos, acrescidos do substrato a ser testado, meio de cultura e inóculo microbiano ruminal. Através de uma equação desenvolvida especificamente para determinados laboratórios, transforma pressão em volume. Essa 
técnica permite a avaliação de grande número de amostras, tem relativo baixo custo e alta repetibilidade. Dessa forma, pode ser utilizada como metodologia para estudos de triagem e seleção de forrageiras.

Quando um alimento é incubado in vitro com o fluido ruminal tamponado, os carboidratos são fermentados com a produção de ácidos graxos voláteis (AGV), como acetato, butirato e propionato, gases (principalmente $\mathrm{CO}_{2}, \mathrm{CH}_{4} \mathrm{e} \mathrm{N}_{2}$ ) e células microbianas (Ørskov et al., 1980). Os ácidos graxos voláteis reagem com o tampão bicarbonato, liberando $\mathrm{CO}_{2}$ e produzindo gases indiretamente à digestão da fibra (Blümmel \& Ørskov, 1993). Para se processar a digestão, os microrganismos devem penetrar as barreiras resistentes da superfície das partículas de alimentos, para alcançarem seus substratos preferidos (France et al., 1993). Segundo McDonald (1981), o grau no qual os microorganismos se fixam e penetram estas barreiras físicas é refletido no tempo de colonização que caracteriza a digestão ruminal de vários alimentos. Segundo Getachew et al. (1998), anaerobiose, temperatura, $\mathrm{pH}$ e tamponamento adequados são fatores importantes na fermentação in vitro. Esses fatores afetam a fermentação dos alimentos pelos microorganismos ruminais e, conseqüentemente, a produção de gases.

O objetivo deste estudo foi avaliar a qualidade nutricional de quatro genótipos de sorgo de duplo propósito, utilizados para silagem, pela técnica in vitro semi-automática de produção de gases.

\section{Material e Métodos}

Quatro genótipos de sorgo (Sorghum bicolor (L). Moench) foram selecionados a partir de um conjunto de vinte e cinco genótipos produzidos pela Embrapa Milho e Sorgo em Sete
Lagoas, MG. Estes apresentaram adequados valores de produção de matéria seca (PMS), proteína bruta (PB), fibra em detergente neutro (FDN) e fibra em detergente ácido (FDA), para futuro uso em silagens. Para essa seleção foi utilizada a análise multivariada, com base em variáveis canônicas (Johnson \& Wichern, 1992), na qual se estimou a máxima correlação entre dois complexos de variáveis, compostas por combinações lineares dos vários caracteres que os constituem. Desse modo, este tipo de análise permite avaliar as inter-relações entre dois complexos determinados por um número arbitrário de caracteres.

Os genótipos de sorgo foram plantados e colhidos em área da Embrapa Milho e Sorgo. O plantio foi realizado com três repetições por híbrido. Cada repetição foi constituída de parcelas de duas fileiras de cinco metros de comprimento, com $0,70 \mathrm{~m}$ de espaçamento. $\mathrm{O}$ corte foi realizado em fevereiro de 2002, quando os grãos se encontravam em estádio de grãos leitosos/pastosos. Em cada repetição foram desprezados $1 \mathrm{~m}$ nas extremidades dos canteiros. As amostras présecadas de cada tratamento foram moídas em moinho estacionário tipo "Thomas-Willey", modelo 4, usando peneira de abertura de malha de 1 $\mathrm{mm}$, sendo posteriormente acondicionadas em recipientes plásticos com tampa, identificados e armazenados para estudos in vitro.

Os genótipos selecionados foram:

ATF53*9929036, com 9,69 t/ha de PMS, 5,99\% de PB, 65,30\% de FDN e 35,65\% de FDA;

ATF54*9929036, com 14,17 t/ha de PMS, 7,73\% de PB, 68,80\% de FDN e 35,91\% de FDA;

CMSXS217*9929012, com 12,50 t/ha de PMS, 8,26\% de PB, 64,94\% de FDN e 30,99\% de FDA; 
Volumax, com 26,09 t/ha de PMS, 5,54\% de PB, $67,33 \%$ de FDN e 33,94\% de FDA.

As fermentações foram realizadas em frascos de $160 \mathrm{~mL}$, previamente lavados com água destilada e posteriormente secados em estufa, segundo Maurício et al . (1999). Visando a manutenção das fermentações anaeróbicas, todos os frascos foram injetados com $\mathrm{CO}_{2}$ anteriormente à adição do substrato, o qual foi pré-secado a $50{ }^{\circ} \mathrm{C}$, por $48 \mathrm{~h}$, e moído a $1 \mathrm{~mm}$. Para não exceder a capacidade tamponante durante as fermentações, não foi adicionado mais que 1 grama (matéria seca) por frasco (Beuvink \& Spoelstra, 1992).

Para cada frasco, previamente lavado com água destilada e secado em estufa, foram adicionados $90 \mathrm{~mL}$ de meio de cultura (Theodorou et al., 1994), composto por solução macromineral $\left(9,5 \mathrm{~g} / \mathrm{L}\right.$ de $\mathrm{Na}_{2} \mathrm{HPO}_{4} .12 \mathrm{HsO}, 6.2 \mathrm{~g} / \mathrm{L}$ de $\mathrm{KH}_{2} \mathrm{PO}_{4}$ e $0,6 \mathrm{~g} / \mathrm{L} \mathrm{MgSO}_{4} .7 \mathrm{H}_{2} \mathrm{O}$ ), solução micromineral (132 $\mathrm{g} / \mathrm{L}$ de $\mathrm{CaCl}_{2} \cdot 2 \mathrm{H}_{2} \mathrm{O}, 100 \mathrm{~g} / \mathrm{L} \mathrm{de}$ $\mathrm{MnCl}_{2} \cdot 2 \mathrm{H}_{2} \mathrm{O}, 10 \mathrm{~g} / \mathrm{L} \mathrm{de} \mathrm{CoCl}_{2} \cdot 6 \mathrm{H}_{2} \mathrm{O}$ e $80 \mathrm{~g} / \mathrm{L}$ de $\mathrm{FeCl}_{3} \cdot 6 \mathrm{H}_{2} \mathrm{O}$ ) solução tampão $\left(4 \mathrm{~g} / \mathrm{L}\right.$ de $\mathrm{NH}_{4} \mathrm{CO}_{3}$ e $35 \mathrm{~g} / \mathrm{L}$ de $\left.\mathrm{NaHCO}_{3}\right)$, indicador $(0,01 \mathrm{~g} / \mathrm{L}$ de Rezasurina) e agente redutor (625 mg de cisteína $\mathrm{HCl}, 95 \mathrm{~mL}$ água destilada, $4 \mathrm{~mL}$ de $1 \mathrm{M} \mathrm{NaOH}$ e $625 \mathrm{mg}$ de $\mathrm{Na}_{2} \mathrm{~S} .9 \mathrm{H}_{2} \mathrm{O}$ ), sendo este preparado minutos antes do preparo total da solução. As soluções foram misturadas na seguinte ordem e proporção: $500 \mathrm{~mL}$ de água destilada, $200 \mathrm{~mL}$ de solução tampão, 200 mL solução macro-mineral, $60 \mathrm{~mL}$ de meio redutor, $0,1 \mathrm{~mL}$ de solução micro-mineral e $1 \mathrm{~mL}$ de solução indicadora. Para evitar qualquer tipo de fermentação, os frascos foram colocados em geladeira e mantidos a $4{ }^{\circ} \mathrm{C}$ durante a noite. Cinco horas antes da inoculação, os frascos foram removidos da geladeira e levados para estufa a $39^{\circ} \mathrm{C}$.

Foi utilizado o líquido ruminal de dois bovinos adultos, machos castrados, mestiços ho- landês e fistulados no rúmen, mantidos em dieta com capim elefante (Pennisetum purpureum) à vontade, mais dois kg de concentrado comercial contendo $20 \%$ de PB e sal mineral e água à vontade oferecidos no cocho. A adaptação do animal à dieta foi realizada 15 dias antes da coleta. O líquido ruminal (inóculo) foi retirado manualmente de várias partes do rúmen, filtrado em camada dupla de gases e acondicionado em garrafa térmica pré-aquecida com água a $39^{\circ} \mathrm{C}$. O inóculo foi submetido a análise física e de atividade microbiana. A coleta foi realizada duas horas antes da alimentação do animal (Theodorou et al., 1994).

No laboratório, o líquido ruminal foi filtrado, passando por uma peneira de náilon, sob injeção contínua de $\mathrm{CO}_{2}$ e mantido em banhomaria, a $39^{\circ} \mathrm{C}$. Em cada frasco, $10 \mathrm{~mL}$ do inóculo preparado foram injetados usando uma seringa graduada e agulha. Logo após a injeção do inóculo, a agulha foi mantida fixada na tampa por alguns segundos, para que eventuais gases injetados ou mesmo formados dentro dos frascos fossem eliminados (pressão zero). Em seguida, os frascos foram manualmente agitados e colocados em estufa a $39^{\circ} \mathrm{C}$ (tempo zero).

Foi adicionado $1 \mathrm{~g}$ de amostra por frasco de fermentação de $160 \mathrm{~mL}$, juntamente com 90 $\mathrm{mL}$ de meio de cultura e $10 \mathrm{~mL}$ de inóculo ruminal. Após a inoculação, os frascos foram mantidos em estufa a $39^{\circ} \mathrm{C}$. A agulha acoplada ao transdutor de pressão foi inserida através da tampa de borracha e a pressão transformada em dados de volume, segundo equação determinada por Maurício et al. (2001), para medição dos gases nos tempos citados. O transdutor foi, então, removido e a agulha mantida inserida à tampa por alguns segundos, para completa estabilização entre pressão interna e externa. Esse processo foi repetido em todos os frascos de cada ban- 
deja (28 frascos por bandeja), que eram agitadas manualmente e recolocadas na estufa.

No final de cada período pré-determinado da fermentação $(6,12,24,48,96$ horas $)$, os frascos foram removidos da estufa e levados para geladeira $\left(4^{\circ} \mathrm{C}\right)$, para interrupção da fermentação. O material sólido e líquido de cada frasco foi filtrado em cadinhos de filtragem (porosidade 1), usando uma bomba de vácuo. Esses cadinhos foram, então, mantidos por 48 horas em estufa de $105^{\circ} \mathrm{C}$, sendo posteriormente pesados e o peso utilizado para o cálculo da degradabilidade da MS. Os parâmetros do modelo proposto por France et al . (1993) para descrever o potencial máximo de produção de gases (A), "lag phase" $(L)$, e a taxa de produção de gases $(\mu)$ foram obtidos utilizando-se o programa MLP (Maximun Likelihood Program), segundo Ross (1987).

As produções acumuladas de gases foram analisadas utilizando-se delineamento experimental de blocos ao acaso, em esquema de par- celas subdivididas. Foram utilizadas dois inóculos como blocos, os genótipos como parcelas e os tempos de incubação como subparcelas. As médias foram comparadas pelo teste de agrupamentos de Scott-Knott, a 5\% de probabilidade, através do programa SAEQ 8.0.

\section{Resultados e Discussão}

As produções acumulativas de gases após os tempos de incubação dos genótipos estudados são apresentadas na Tabela 1, pela qual se nota que, não foi observada nenhuma variação significativa entre os genótipos, para um mesmo período de incubação. A comparação entre períodos, para um mesmo híbrido, mostrou-se com produções acumuladas crescentes de gases $(\mathrm{p}<0,05)$, até as $72 \mathrm{~h}$ de incubação, com as médias de 19,8; 54,$5 ; 116,5 ; 182,8$ e $217,5 \mathrm{~mL} / \mathrm{g}$ de $\mathrm{MS}$, para os tempos de incubação $6,12,24,48,72 \mathrm{~h}$, respectivamente. A produção média para o período de $96 \mathrm{~h}$ foi de $227,5 \mathrm{~mL} / \mathrm{g}$ de MS e não apresentou

TABELA 1. Produções acumulativas de gases (mL/g de MS) dos genótipos estudados após os tempos de incubação de 6, 12, 24, 48, 72 e 96 horas

\begin{tabular}{lcccccc}
\hline & \multicolumn{5}{c}{ Tempo de incubação (h) } \\
\cline { 2 - 6 } \multicolumn{1}{c}{ Genótipos } & 6 & 12 & 24 & 48 & 72 & 96 \\
\hline ATF53*9929036 & $20 \mathrm{Ae}$ & $53 \mathrm{Ad}$ & $113 \mathrm{Ac}$ & $179 \mathrm{Ab}$ & $215 \mathrm{Aa}$ & $226 \mathrm{Aa}$ \\
ATF54*9929036 & $19 \mathrm{Ae}$ & $54 \mathrm{Ad}$ & $117 \mathrm{Ac}$ & $180 \mathrm{Ab}$ & $212 \mathrm{Aa}$ & $224 \mathrm{Aa}$ \\
CMSXS217*9929012 & $18 \mathrm{Ae}$ & $52 \mathrm{Ad}$ & $115 \mathrm{Ac}$ & $186 \mathrm{Ab}$ & $222 \mathrm{Aa}$ & $231 \mathrm{Aa}$ \\
Volumax & $22 \mathrm{Ae}$ & $59 \mathrm{Ad}$ & $121 \mathrm{Ac}$ & $186 \mathrm{Ab}$ & $221 \mathrm{Aa}$ & $229 \mathrm{Aa}$ \\
\hline Média & 19,8 & 54,5 & 116,5 & 182,8 & 217,5 & 227,5 \\
\hline
\end{tabular}

Médias seguidas de letras maiúsculas iguais na coluna e de letras minúsculas iguais na mesma linha não diferem pelo teste Scott-Knott $(\mathrm{P}>0,05)$. CV $=9,3 \%$.

diferenças $(\mathrm{p}>0,05)$ em relação aos valores observados às $72 \mathrm{~h}$ de incubação, para todos os híbridos. As semelhanças para as comparações entre genótipos impossibilitam destacar os que sofreram maior fermentação nos distintos tempos de incubação, enquanto as semelhanças ( $\mathrm{p}>$ 0,05), obtidas para os dois últimos períodos de incubação, indicam a estabilização da produção acumulada de gases, a partir de 72 horas de fermentação, mostrando que as incubações por $72 \mathrm{e}$ 
$96 \mathrm{~h}$ foram suficientes para atingir os valores máximos de produção acumulada de gases.

Nesse ensaio, observaram-se altos coeficientes de determinação $\left(r^{2}=0,99\right)$ entre os valores de produção acumulativa de gases (PCG) e degradabilidade da matéria seca (DMS), e que demonstra que as curvas de produções de gases de cada substrato incubado refletem a degradação da matéria seca, o que reforça a confiabilidade da técnica em descrever a cinética de fermentação de substratos. Essas elevadas correlações também foram descritas por Maurício et al. (2003) e Rodrigues et al. (2002), ao avaliarem diferentes silagens de sorgo pela técnica in vitro semi-automática de produção de gases.
As equações de regressão entre os resultados de PCG e DMS obtidas foram:

$$
\begin{aligned}
\text { vol }= & 4,27644-17,5288 * \mathrm{dms}\left(r^{2}=0,99\right) \\
& \text { ATF53*9929036; } \\
\text { vol }= & 4,66585-35,7644 * \mathrm{dms}\left(r^{2}=0,99\right) \\
& \text { ATF54*9929036; } \\
\text { vol }= & 4,42512-19,0051 * \mathrm{dms}\left(r^{2}=0,99\right) \\
& \text { CMSXS217*9929012 e } \\
\text { vol }= & 4,58472-26,7382 * \mathrm{dms}\left(r^{2}=0,99\right) \\
& \text { VOLUMAX. }
\end{aligned}
$$

$\mathrm{Na}$ Figura 1, podem ser observadas as curvas de produção acumulativa de gases dos quatro genótipos de sorgo avaliados.

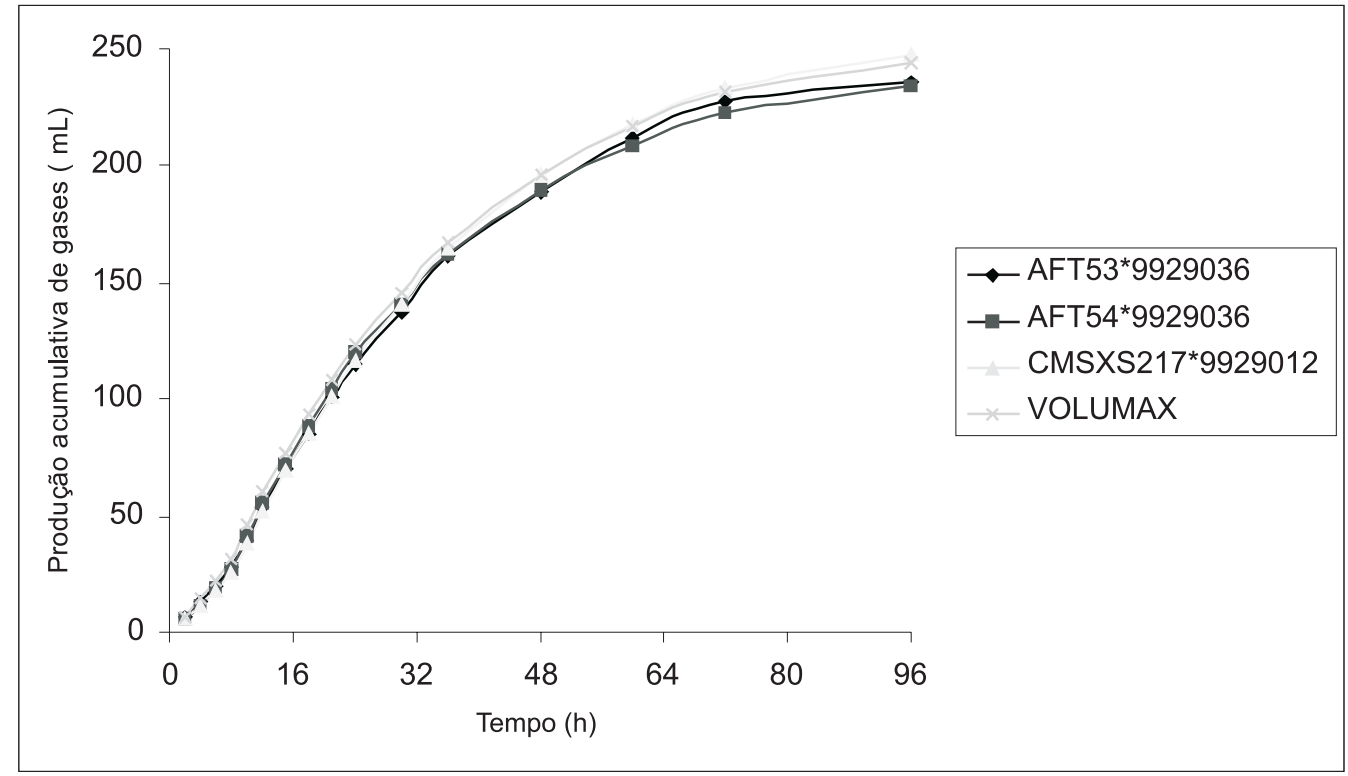

Equações: $y=2,4383 x+27,83$ (ATF53*9929036); $y=2,4325 x+28,517$ (ATF54* 9929036); $\mathrm{y}=2,5889 \mathrm{x}+25,921(\mathrm{CMSXS} 217 * 9929012) ; \mathrm{y}=2,5271 \mathrm{x}+31,065($ VOLUMAX)

FIGURA 1. Curvas de produção acumulativas de gases dos quatro genótipos de sorgo

Nota-se graficamente que os genótipos estudados apresentaram o mesmo perfil de produção de gases até, aproximadamente, as $32 \mathrm{~h}$ de fermentação; a partir desse horário começa a haver uma dife- renciação entre a produção de gases. Graficamente, pode ser observada a superioridade do genótipo CMSXS217*9929012, seguido do Volumax, em relação aos demais, às $96 \mathrm{~h}$ de fermentação. 
Na Figura 2, encontram-se as taxas de produção de gases dos quatro genótipos de sorgo avaliados nos diferentes tempos de fermentação.

As maiores taxas de produção de gases foram obtidas após 16 horas de fermentação. Esse processo pode ser explicado pela degradação da fração solúvel de rápida fermentação (Beuvink \& Kogut, 1993), que se encontra principalmente constituída por proteínas, minerais, ácidos orgânicos, açúcares simples e alguns polissacarídeos não estruturais. Entre os períodos de fermentação de 32 a 48 horas, observa-se (Figura. 2) uma elevação na taxa de produção de gases, provavelmente, devido à degradação da fração lentamente fermentável (carboidratos estruturais).

A fração solúvel constitui um substrato energético de rápida fermentação para os micror-

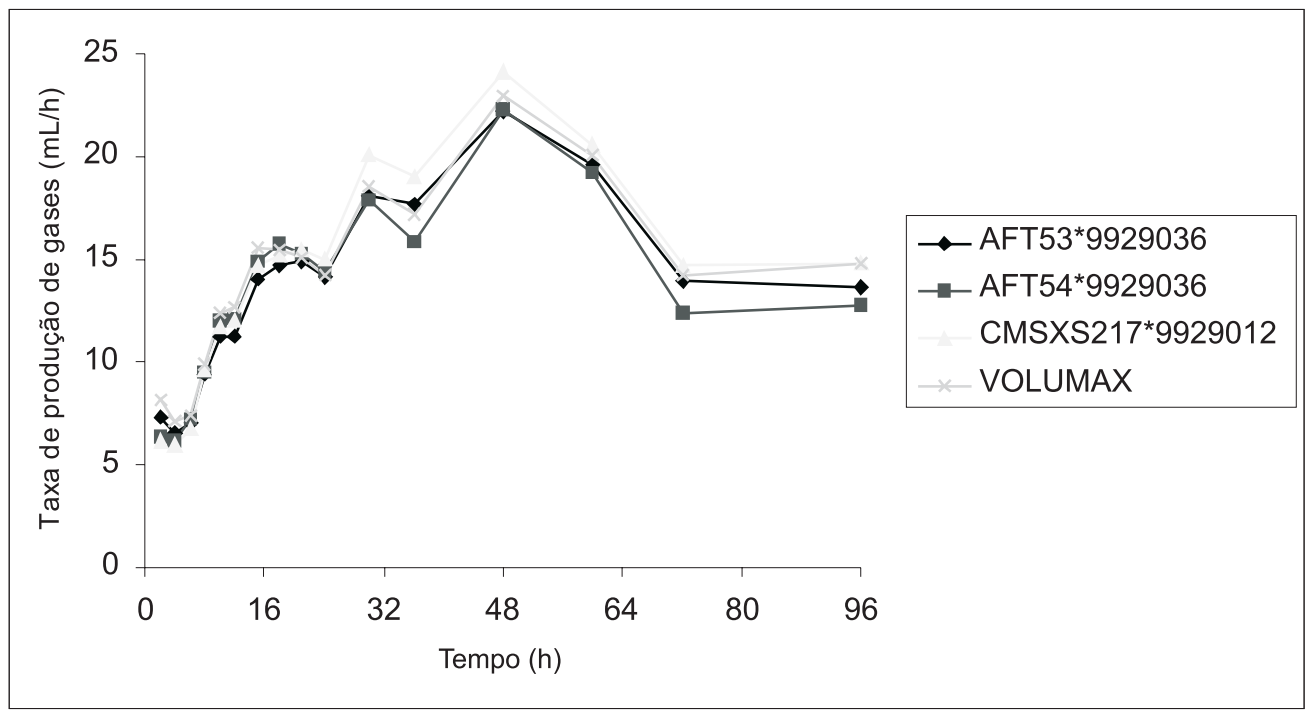

Equações: $\mathrm{y}=0,094 \mathrm{x}+10,775$ (ATF53*9929036); $\mathrm{y}=0$ 0,0782x + 11,127 (ATF54* 9929036); $\mathrm{y}=0,1109 \mathrm{x}+10,919(\mathrm{CMSXS} 217 * 9929012) ; \mathrm{y}=0,0921 \mathrm{x}+11,451($ VOLUMAX)

FIGURA 2. Taxas de produção de gases dos quatro genótipos de sorgo avaliados nos diferentes tempos de fermentação.

ganismos, facilitando, assim, os processos de adesão e colonização do substrato, mas sua importância começa a diminuir com o transcorrer do tempo, quando uma maior quantidade de constituintes da parede celular tornam-se disponíveis (Jung \& Deetz, 1993; Soest, 1994)

O potencial máximo de produção de gases, o tempo de colonização, a taxa de fermentação e a degradabilidade da matéria seca (DMS), após $96 \mathrm{~h}$ de fermentação, obtidos para os quatro genótipos, são apresentados na Tabela 2.
A taxa de produção e o potencial máximo de produção de gases não foram significamente influenciados pelos genótipos. A média geral para a taxa de produção de gases foi de $0,037 \mathrm{~mL} / \mathrm{g}$ de $\mathrm{MS} / \mathrm{h}$, variando de 0,034 (CMSXS217*9929012) a 0,043 mL/g de MS/h (Volumax) e a média para o potencial máximo de produção foi de $236 \mathrm{~mL} / \mathrm{g}$ de MS, variando de 227 (ATF54* 9929036) a $241 \mathrm{~mL} / \mathrm{g}$ de $\mathrm{MS}$ (Volumax). Foram também observadas semelhanças estatísticas entre a DMS dos quatro genótipos 
TABELA 2. Parâmetros de produção de gases estimados, pelo modelo de France et al. (1993), de quatro genótipos de sorgo avaliados.

\begin{tabular}{|c|c|c|c|c|}
\hline Genótipos & $A(\mathrm{~mL} / \mathrm{g} \text { de } M S)^{a}$ & L (h:min) ${ }^{b}$ & $\mu(\mathrm{mL} / \mathrm{g} \text { de } M S / h)^{c}$ & DMS96 $(\%)^{d}$ \\
\hline ATF53*9929036 & $233 \mathrm{~A}$ & $1: 50 \mathrm{~A}$ & $0,036 \mathrm{~A}$ & $56,8 \mathrm{~A}$ \\
\hline ATF54* 9929036 & $227 \mathrm{~A}$ & $1: 51 \mathrm{~A}$ & $0,038 \mathrm{~A}$ & $56,2 \mathrm{~A}$ \\
\hline CMSXS217*9929012 & $243 \mathrm{~A}$ & $1: 72 \mathrm{~A}$ & $0,034 \mathrm{~A}$ & $57,8 \mathrm{~A}$ \\
\hline Volumax & $241 \mathrm{~A}$ & $1: 16 \mathrm{~A}$ & $0,043 \mathrm{~A}$ & $56,0 \mathrm{~A}$ \\
\hline Média & 236 & $1: 47$ & 0,037 & 56,7 \\
\hline
\end{tabular}

Médias seguidas por letras iguais, em uma mesma coluna, não diferem entre si pelo teste $\operatorname{Scott}-\mathrm{Knott}(\mathrm{p}>0,05)$. ${ }^{\mathrm{a}} \mathrm{CV}=$ $7,3 \%,{ }^{\mathrm{b}} \mathrm{CV}=13,2 \%,{ }^{\mathrm{c}} \mathrm{CV}=9,7 \%,{ }^{\mathrm{d}} \mathrm{CV}=5,9 \%$.

A - Potencial máximo de produção de gases, $\mathrm{L}$ - tempo de colonização, $\mu$-Taxa de fermentação, DMS96-degradabilidade in vitro da matéria seca após $96 \mathrm{~h}$.

(Tabela 1), com uma média geral de $56,7 \%$, resultados estes que estão aliados à similaridade entre os volumes de gases produzidos.

Para o parâmetro tempo de colonização ou lag phase (L), não houve efeito do genótipo, que foi de 1 h e $16 \min$ (Volumax) a 1 h e 72 min (CMSXS217*9929012). Esse parâmetro representa o tempo compreendido entre o início da incubação e a ação microbiana sobre a amostra testada. As reduções no tempo de colonização são favorecidas pela presença de substratos prontamente fermentáveis e por características físicas e químicas da parede celular da amostra, capazes de facilitar a colonização microbiana.

Blümmel \& Ørskov (1993) analisaram resultados obtidos através da técnica de produção de gases, sugerindo que, quando a taxa de fermentação é somada à degradabilidade do substrato, obtém-se maior coeficiente de correlação com o consumo voluntário. Os gases produzidos na fermentação refletem a degradação da amostra avaliada; a taxa e o potencial máximo de produção de gases são, provavelmente, os principais parâmetros para avaliar a qualidade de forragens pela técnica de produção de gases. Dessa forma, forragens mais fermentáveis, ou digestíveis, seriam aquelas que apresentam altos valores de potencial máximo de fermentação em menor tempo.

\section{Conclusões}

Pela avaliação dos parâmetros obtidos através do modelo de France et al. (1993), podemos considerar que, dentre os genótipos avaliados, o Volumax possui maior potencial para produção de silagem, por apresentar menor lag phase e maior taxa de fermentação.

\section{Literatura Citada}

BEUVINK, J. M. W.; SPOELSTRA, S. F. Interactions between abstrate, fermentation end products, buffering systems and gas production upon fermentation of different carboydrates by mixed rumen microorganisms in vitro. Applied Microbiology and Biotechnology, Berlin, v. 37, n.4, p. 505-509, 1992.

BEUVINK, J. M. W.; KOGUT, J. Modelling gas production Kinetics of grass silages incubated with buffered ruminal fluid. Journal of Animal Science, Champaign, v. 741, p. 1041-1046, 1993.

BLÜMMEL, M.; ØRSKOV, E. R. Comparison of gas production and nylon bag degradability of roughages in predicting feed intake in cattle. 
Animal Feed Science and Technology, Amsterdam, v. 40, p. 109-119, 1993.

BRITO, C. J. F. A.; RODELLA, R. A.; DESCHAMPS, F. C. et al. Anatomia quantitativa e degradação in vitro de tecidos em cultivares de capim-elefante. Revista Brasileira de Zootecnia, Viçosa, v. 28, n. 2, p. 223-229, 1999.

CABRAL, L. S.; VALADARES FILHO, S. C.; DETMANN, E. et al. Cinética ruminal das frações de carboidratos, produção de gases, digestibilidade in vitro da matéria seca e NDT estimado da silagem de milho com diferentes proporções de grãos. Revista Brasileira de Zootecnia, Viçosa, v. 31, n. 6, p. 2332-2339, 2002 .

CÂNDIDO, M. J. D.; OBEID, J. A.; PEREIRA, O. G. et al. Valor nutritivo de silagens de híbridos de sorgo (Sorghum bicolor (L.) Moench) sob doses crescentes de adubação. . Revista Brasileira de Zootecnia, Viçosa, v. 31, n. 1, p. 20-29, 2002.

FRANCE, J.; DHANOA, M. S.; THEODOROU, M. K. A model to interpret gas accumulation profiles whit "in vivo" degradation of ruminants feeds. Journal of Theorical Biology, London, v. 163, p. 99-111, 1993.

GETACHEW, G.; BLÜMMEL, M.; MAKKAR, H. P. S. et al. In vitro gas measuring techniques for assessment of nutritional quality of feeds: a review. Animal Feed Science and Technology, Amsterdam, v. 27, p. 261-281, 1998.

JOHNSON, R. A.; WICHERN, D. W. Applied multivariate statistical analysis, 3. ed. New York: Prentice_Hall, 1992. 642 p.

JUNG, H. G.; DEETZ, D. A. Cell wall lignification and degradabilit. In: JUNG, H. G.;
BUXON, D. R.; HATIFIELD, R. D. et al. Eds. Forage cell wall structure and digestiility. Madison: Americam Society of Agronomy: Crop Science Society of America: Soil Science Society of America, 1993. p. 315-346.

MALAFAIA, P. A. M.; VALADARES FILHO, S. C.; VIEIRA, R. A. M. et al. Cinética ruminal de alguns alimentos investigada por técnica gravimétricas e metabólicas. Revista Brasileira de Zootecnia, Viçosa, v. 27, n. 6, p. 370-380, 1998.

MAURÍCIO, R. M.; MOULD, F. L.; DHANOA, M. S. et al. A semi-automated in vitro ga production technique for ruminants feedstuf avaluation. Animal Feed Science and Technology, Amsterdam, v. 29, p. 321-330, 1999. MAURÍCIO, R. M.; PEREIRA, L. G. R.; GONÇALVES, L. C. et al. Obtenção da equação quadrática entre volume e pressão para implantação da técnica in vitro semi-automática de produção de gases para avaliação de forrageiras tropicais. In: REUNIÃO ANUAL DA SOCIEDADE BRASILEIRA DE ZOOTECNIA, 38., 2001. Piracicaba. Anais... Piracicaba: SBZ, 2001. p. 1345-1346.

MAURÍCIO, R. M.; PEREIRA, L. G. R.; GONÇALVES, L. C. et al. Relação entre pressão e volume para implantação da técnica en vitro semiautomática de produção de gases na avaliação de forrageiras tropicais. Arquivo Brasileiro de Medicina Veterinária e Zootecnia, Belo Horizonte, v. 55, p. 216-219, 2003.

McDONALD, I. A revised model for the estimation of protein degradability in the rumen. Journal of Agriculture Science, Cambridge. v. 96, p. 251-252, 1981. 
ØRSKOV, E. R., HOVELL, F. D. D., MOULD, F. Uso de la técnica de la bolsa de náilon para la valuación de los alimentos. Producción Animal Tropical, Santo Domingo, v. 5, p. 213-233, 1980.

$\varnothing \mathrm{RSKOV}, \mathrm{E} . \mathrm{R}$. Dynamics of nitrogen in the rumen. In: ØRSKOV, E. R. Protein nutrition in ruminants. 2. ed. London: Academic Press, 1992. cap. 3, p. 43-93.

PEDREIRA, M. S.; REIS, R. A.; BERCHIELLI, T. T. et al. Características Agrônomicas e Composição Química de Oito Híbridos de Sorgo (Sorghum bicolor (L.) Moench). Revista Brasileira de Zootecnia, Viçosa, v. 32, n. 5, p. 10831092, 2003.

PELL, A. N.; SCHOFIELD, P. Computerized monitoring of gas production to measure forage digestion in vitro. Journal of Dairy Science, Champign, v. 76, p. 1063-1073, 1993.

RODRIQUES, J. A. S.; PIRES, D. A. A.; GONÇALVES, L. C. et al. Avaliação das silagens de quatro genótipos de sorgo pela técnica in vitro semi-automática de produção de gases. In: CONGRESSO NACIONAL DE MILHO E SORGO, 24, 2002, Florianópolis. Meio ambiente e a nova agenda para 0 agronegócio de milho e sorgo: [resumos expandidos]. Sete Lagoas: ABMS: Embrapa Milho e Sorgo: Epagri, 2002. CD-ROM. Seção Trabalhos.
ROSS, G. J. S. Maximun Likelihood Program: a Manual. Hampendon: Tothmseted Experimental Station, 1987.85 p.

RUSSEL, J. B.; O'CONNOR, J. D. L.; FOX, D. G. et al. A net carbohydrate and protein system for evaluating cattle diets: I. Rminal fermentation. Journal of Animal Science, Champaign, v. 70, n. 12, p. 3551-3561, 1992.

SCHOFIELD, P.; PITT, R. E.; PELL, A. N. Kinetics of fiber digestion from in vitro gas production. Journal of Animal Science, Champaign, v. 72, n. 11, p. 2980- 2991, 1994.

SOEST, P. J. van. Nutritional ecology of the ruminant. 2. ed. Ithaca: Cornell University Press, 1994. $476 \mathrm{p}$.

THEODOROU, M. K.; WILLIAMS, B. A.; DHANOA, M. S. A simple gas production method using a pressure transducer to determine the fermentation kinetics of ruminant feeds. Animal Feed Science and Technology, Amsterdam, v. 48, p. 185-197, 1994.

TILLEY, J. M. A.; TERRY, R. A. A two-stage technique for the digestion of forage crops. Journal British Grass- land Society, Aberystwyth, v. 18, p. 104-111, 1963.

VEGA, S.; ESPERANCE, M. Sorgo forrageiro (Sorghum bicolor). Pastos y Forajes, Habana, v. 7, p. 121, 1984. 